\title{
Language Revitalization: A Case Study of the Khoisan Languages
}

\author{
Xinyi Yuan ${ }^{1}$ \\ ${ }^{1}$ Shanghai Foreign Language School, Affiliated with Shanghai International Studies University, Endangered \\ Languages and Language Revitalization, China \\ Correspondence: Xinyi Yuan, Shanghai Foreign Language School, Affiliated with Shanghai International \\ Studies University, Endangered Languages and Language Revitalization, China. E-mail: amy000927@163.com
}

Received: June 28, 2020 Accepted: July 27, 2020 Online Published: July 31, 2020

doi:10.5539/ells.v10n3p79 URL: https://doi.org/10.5539/ells.v10n3p79

\begin{abstract}
This paper introduces the concept of endangered languages and the corresponding solution of language revitalization. It first illustrates the importance of language preservation and the process of language endangerment and death. The two principal strategies of thwarting language death are discussed, with an emphasis on the language revitalization as the more effective option due to the difficulties that language revival faces. The most commonly successful approaches to language preservation are discussed such as establishing cultural pride and identity, education, and utilizing modern technology. These strategies are discussed in detail through the presentation of a case study: the Khoisan language family.
\end{abstract}

Keywords: language revitalization, language death, Khoisan languages

\section{Introduction}

Just like their speakers, languages can also die. When a language is categorized as "dead", it means that it has no living speakers. It may be hard for many people to envision such a possibility; however, linguist David Crystal has estimated that "one language [is] dying out somewhere in the world, on average, every two weeks" (Crystal, 2008).

There are four language statuses: safe, endangered, moribund, and dead. The most widely spoken languages are considered "safe" - these are generally languages that are officially adopted by national governments and possess more than 100,000 native speakers. Endangered languages refer to languages that future generations would cease to learn. In this case, even if a language currently has many speakers, the number of living speakers may dwindle to nothing after only a few generations if no measures are taken to preserve the language. Moribund languages are in the last stage before language death. For these languages, the only native speakers left are elders who may die in the near future. Finally, if all native speakers die and there are no younger generations who use the language, the language ceases to have native speakers and is considered dead (Isa et al., 2014).

There are two main types of language death: instant language death and the gradual degradation of a language. The former is usually caused by large-scale events that kill the whole ethnic group, such as genocide, natural disasters, and diseases like the bubonic plague. These situations are rare. Languages more commonly undergo a gradual process of death in which they lose native speakers over time and ultimately become extinct, often as a result of multiple contributing factors. For example, as people migrate toward bigger cities, aboriginal languages can easily become moribund as the speakers disperse. Alternatively, a language may also become extinct if the government of the region sets another dominant language as the official language. As more people speak the official language for better economic development, their children become less likely to learn their parent's mother tongue, leading to the eventual death of the marginalized language (The Death of Language, n.d.).

\section{Language Revitalization and Revival}

The loss of a language constitutes more than the mere retirement of a communicative tool-it also represents the loss of history and culture. Therefore, it is important to prevent language death. Language revitalization is the process of rejuvenating a language's use in order to prevent its extinction (Crystal, 2000). In this strategy, third parties such as linguists and/or government officials intervene in order to encourage or develop more native speakers in the target language. In Language Death, Anthropologist Akira Yamamoto identifies nine factors that he believes will help prevent language death: 
1) There must be a dominant culture that favors linguistic diversity

2) The endangered community must possess an ethnic identity that is strong enough to encourage language preservation

3) The creation and promotion of programs that educate students on the endangered language and culture

4) The creation of school programs that are both bilingual and bicultural

5) The establishment of teacher training programs for native speakers

6) The endangered speech community must be completely involved

7) The creation of language materials that are easy to use

8) The language must have written materials that encompass new and traditional content

9) The language must be used in new environments and the geographical areas the language is used (both old and new) must be strengthened (Crystal, 2000, p. 191).

This process goes by a different name depending on the stage of language death: when a language is in danger, it is called revitalization, but when a language has already become extinct, it is called revival. These two strategies require different approaches. For revitalization, researchers must expand the number of speakers by promoting the language's use; for revival, researchers must attempt to motivate a group to start learning the language, relying on the materials left by previous speakers. There has been only one successful example of language revival to date-modern Hebrew (Harshav, 2009). This revival was unique in that it was enabled by a shared cultural identity and commitment to using Hebrew in daily life due to the strong religious belief tied to the language. Currently, there are only a few successful cases of language revitalization, such as Ainu in Japan, Manchu in China, or Quechua in Peru (Alicia, 2018). In general, language revitalization is much more effective than language revival - languages are more likely to be saved when they still have speakers.

\section{Khoisan Language Family Overview}

\subsection{Name}

The word "Khoisan" is made up of the roots "Khoe" and "San" from the Khoekhoe language. The word "Khoe" represents "person" in the Khoekhoe language, one of the most historically widespread non-Bantu languages in Africa. The word "San" is a Khoekhoe word for "gatherers" (Greenberg, 1963).

\subsection{History}

Compared to most current languages, the Khoisan language is quite old. In 2012, a team from the University of Auckland in New Zealand estimated that Proto-Indo-European perhaps originated 8,000 to 9,500 years ago. Archaeological evidence also suggests that there were people who spoke Khoisan languages in Southern Africa about 60,000 years ago, implying that Khoisan languages may be the most ancient of all human tongues (Thompson, 2015).

\subsection{Notable Features}

The Khoisan language family is a distinct African language group characterized by its click consonants. These languages are also known for their rich phonological inventories, which possess more phonemes than any other language in the world. For example, the Jul'hoan language has 48 click consonants and nearly as many non-click consonants. It also has strident and pharyngealized vowels, as well as four tones. The !Xóõ and fHõã languages are even more phonologically rich. Overall, the term "Khoisan" now generally serves as a term for the Non-Bantu and Non-Cushitic "click languages" in Africa (Miller-Ockhuizen,2003).

\subsection{Geographical Distribution and Effects Thereof}

The Khoisan language family is used by several ethnic groups of southern Africa, despite being the smallest of the African language families. Khoisan language regions have been separated by political boundaries - territory lines and various national borders. As a result of this division, regional differences have developed, both lexically and grammatically. Although the Khoisan language group is famous for its click sounds, each language and dialect demonstrate variation, whether that variation appears in the grammar, vocabulary, or tone (du Plessis, 2019).

According to combined statistical data from Wikipedia, the Khoisan languages are currently spoken only in Southwestern Africa - in the region around the Kalahari Desert, extending from Angola to South Africa, and in one small area of Tanzania. The largest subset of the Khoisan language family is the KHOE language group, also called "Central Khoisan". Central Khoisan is also the first Khoisan language that spread to the Europeans during 
colonization. As a result, KHOE remains the most systematically documented Khoisan language family, with official scripts and consistent grammar (du Plessis, 2019).

\section{The Endangerment of the Khoisan Languages}

\subsection{The Current State of Khoisan Language Endangerment}

The Khoisan languages have many branches, each with its own unique characteristics. These languages vary with regard to their level of endangerment. Many Khoisan languages have already become extinct. It has been suggested that a language must have 100,000 speakers to be considered "safe". By these standards, about two-thirds of Khoisan languages are considered "at risk". Within this "at risk" group, few languages have more than 1,000 speakers. In each of these "at risk" languages, the number of speakers is diminishing rapidly. As a result, language revitalization is becoming increasingly important for both Khoisan language speakers and linguists (Babel Runs Backward, 2004).

\subsection{Reasons for Khoisan's Endangerment}

The causes of individual Khoisan language endangerment vary but there are some common factors that are acknowledged by most scholars based on recent research. These variables are often intertwined: globalization, urbanization, and language competition. Globalization and urbanization often lead to language competition, which frequently results in speakers abandoning their native language for one with more prestige or economic opportunities. In some cases, abandonment may also be politically motivated (Batibo, 2009).

\subsubsection{Colonization, Diaspora, and Language Abandonment}

Historically speaking, colonization has profoundly influenced local language distribution. The impact of colonization to local Khoisan groups in South Africa can largely be traced back to two major results of the 1885 Berlin Conference, in which Europeans, led by Great Britain and France, began competing for the territory of Africa. In order to maximize their own profits, colonizers arbitrarily divided the African continent with no regard for its extant ethnic and language distinctions and distributions. As a result, pre-existing ethnic groups were separated by the new territory borders. This separation of language speakers led to separate language development, causing the Khoisan language group to diverge into distinct branches (Ajala, 1983).

Colonization had effects on the Khoisan languages beyond separating its speakers. After the Berlin Conference, colonization swept into every corner of Africa, aggressively introducing colonial languages and lowering the social status of the local languages. The English and the French promoted their own languages through education. The cultivation of the prestige of the colonial languages led to language abandonment because Western language use generated higher economic benefits. As such, many speakers chose to abandon their mother tongue in favor of the more economically and socially advantageous languages of the colonizers (Ajala, 1983).

\subsubsection{Language Competition from Urbanization and Globalization}

For Khoisan languages, urbanization led to the migration of its speakers into multilingual and multicultural cities (Chebanne, 2010). Under such population flow, many Khoisan speakers abandoned their native languages to adopt more wide-spread languages such as Swahili and English. This language abandonment has endangered Khoisan languages by limiting the number of speakers.

Similarly, the trend of globalization has led to more gradual language abandonment. Through globalization, people have more contact with other communities, creating cultural exchange. The cultural exchange causes people to not only learn about other cultures, but sometimes even merge their own culture with the cultures around them. For example, intermarriage leads to households in which the parents may speak different mother tongues. When parents communicate with their children at home, they use a shared language. This can be either one of the parent's mother tongues or some wide-spread language such as English or Swahili, which is shared by all parties. Although "children can be bilingual with no difficulty and it doesn't do them any harm, the hard part is making sure they have enough natural exposure to both languages" (Grosjean, 1982, p. 7).

Essentially, in bilingual households, it is difficult for children to have enough exposure to both languages in order to achieve true bilingualism. More commonly, children tend to grow up with a preference for one language, meaning they are less fluent in the other. As such, there is a partial loss of one language in that generation. When these children have children themselves and fail to teach them the less-preferred heritage language, the loss accumulates, diminishing the number of speakers of the dis-preferred language in that family. This process is one example of how Khoisan languages' vitality has weakened compared to other more popular language groups like Bantu languages (Klass, 2017).

While Khoisan languages have been marginalized by popular languages such as English, Swahili, and Bantu 
languages, Khoisan languages also face marginalization from other minority languages, particularly in certain geographical areas. Khosian languages have numerous branches, and there are specific regions where most Khoisan languages are spoken: regions around the Kalahari Desert extending from Angola to South Africa, and part of Tanzania. This geographical concentration makes it much easier for different Khosian languages to influence one another and marginalize certain minority languages, including other Khoisan languages (Bleek \& Lloyd, 1911).

This phenomenon is demonstrable in South Africa, where Khoisan languages are most spoken. For example, two Khoisan languages, Nkoroo and Defaka, experienced competition with one another. Nkoroo was spoken in Nigeria by about 2,000 people and considered severely endangered. Defaka was also endangered, but its speakers shifted to Nkoroo, pushing Defaka to the brink of extinction (Eberhard et al., 2020).

\subsection{Revitalization Strategies in Use for Khoisan Languages}

\subsubsection{Establishing Cultural Pride and Promoting Ethnic Identity}

Ethnic identity is closely linked with language. One reason that people give up their own language is because they lack pride in their language and/or culture, regarding their culture as inferior or economically useless, a belief which is often intentionally fostered by colonial powers. Therefore, pride in one's culture, language, and ethnic identity are required for a person to value preserving their language. As such, encouraging language use as a part of developing cultural pride has historically been an effective means of language revitalization (Whaley, personal communication, August 23, 2019).

\subsubsection{Religion}

One way to encourage language use is translating certain religious books into the endangered language, as demonstrated by the Wycliffe Bible Translators. By combining language use with the power of religion, speakers start to connect their religion with their ethnic identity, which helps them use their mother tongue more often. This method has been useful in the Khoisan community. Since a large percentage of Khoisan-speakers identifies as Christian, the Translator Organization translated the Bible into their dialect (Wycliffe Bible Translators, personal communication, January 28, 2020). The effort was successful, and the Khoisan Bible quickly became a popular book found in most households. Speakers who had abandoned their language re-discovered their mother tongues through reading the translated Bible, which also serves as a reference for future language study by professionals (Wycliffe Bible Translators, personal communication, January 28, 2020).

\subsubsection{Cultural Traditions and Celebrations}

Connecting language with indigenous traditions and festivals also serves to promote ethnic identity for language preservation. This has proven effective for the Nluu language, one of the most studied Khoisan languages. People in the $\$$ Khomani San Community celebrate several indigenous festivals. During these events, attendees only speak N|uu, which allows them to bond with one another and associate the use of their language with these culturally significant celebrations. This encourages both cultural pride and language use, the one supporting the other (Khomani San, n.d.).

\subsubsection{Education}

Another long-term method to revitalize a language is providing sustainable education on and preferably in that language. This is an effective way to ensure that younger generations keep learning the endangered language. Many traditional, ancient Khoisan languages such as Nluu do not have many written records or official scripts to review. This means that the language cannot be recreated from texts but can only be preserved through use by younger generations. The Khoisan language revitalization efforts through education have benefitted many generations, teaching students to treasure their language and culture. While this cultural appreciation may not be calculable, it is valuable (Whaley, 2019).

One of the most successful cases of education revitalization is that of the $\$$ Khomani San Community. The $\$$ Khomani San Community is an indigenous group situated on the outskirts of the Northern Cape. Levi Namaseb, a Khowkhowgowab speaker from the University of Namibia, began these efforts by teaching the younger generation the Nluu language, including its vocabulary, grammar, and cultural practices (Biwa, 2012).

Another prominent figure related to this education program is Katrina Esau. She established a Nluu language school in the $₫$ Khomani San that was modeled after Levi’s teaching and greatly expanded the number of students. Esau hopes to ensure the continuation of the San people's language and culture through the transfer of language and valuable knowledge to younger generations (SABC Education Shows, 2015).

Katrina Esau reports that, while the youth may not understand the value of their endangered language at first, she 
firmly believes that this teaching is necessary. According to her, education can help younger generations realize the importance of preserving their own mother tongue and teach them to treasure their unique identities. She also encourages students to speak Nluu in schools so as to develop greater familiarity with the language. By learning the language in schools instead of through casual instruction by an elder, children are encouraged to deliberately practice what they have learned. Students also have the benefit of normalized language use within their peer groups - their friends and relatives will also speak Nluu, which encourages them to use it in daily life (SABC Education Shows, 2015).

\subsubsection{Technology}

Modern technology can be utilized to assist revitalization, both through the educational system and outside of it (Eisenlohr, 2004). Within the scope of education, technology such as CDs or videos can aid in language instruction. For instance, Katrina Esau intends to use modern technology to assist in the Nluu language revitalization. She plans to create educational CDs and DVDs, so that anyone can learn the Nluu language, regardless of proximity to a Nluu language school (SABC Education Shows, 2015). As the use of technology continues to expand, more reference materials will become available on the internet so that the resources can be accessed across the globe (Eisenlohr, 2004).

\subsection{Additional Suggested Revitalization Strategies}

\subsubsection{Utilization of Modern Technology}

\section{Social Media}

In addition to educational CDs and DVDs, there are other forms of modern technology that can facilitate revitalization. Linguists have proposed the use of public blogs and language channels on social media (Eisenlohr, 2004). In the 21 st century, social media has become a nearly-universal global phenomenon. Websites like Facebook, Twitter, and Instagram, alongside local platforms, play an increasing role in the lives of individuals worldwide - especially younger individuals (Richter, 2018). The internet and social media can be used to foster connections between speakers who are separated by physical distance, as well as to educate the international community at large. For those Khoisan speakers who have migrated to more developed cities or integrated with larger tribes, social media can be used to maintain contact with their indigenous community and native language. This may be especially helpful for those who do not use their mother tongue in their daily lives. Essentially, social media could de-isolate Khoisan speakers and keep them connected to their mother language.

\section{Online Libraries}

Online libraries may also be especially helpful, especially for languages without written scripts, as they contain information in various non-written format such as videos, music, etc. (Eisenlohr, 2004). For example, an online library may facilitate the revitalization of Khoisan languages by providing videos related to pronunciation of its various click sounds or documenting traditional Khoisan songs, effectively circumventing the lack of an orthography. Online libraries or archives could offer people a chance to "borrow" these materials to learn more about Khoisan languages.

\section{Language Learning Apps}

Language learning applications such as Duolingo, Babbel, and Rosetta Stone may also prove helpful for language revitalization. These applications represent a large trend-there are 300 million active users of Duolingo (Duolingo, 2019). Through these applications, native speakers, heritage speakers, and individuals with no connection to the language can all learn and use the language, bolstering the number of speakers and preventing language death. These online sources can also be updated to add new information and old versions can be permanently preserved for future reference. Therefore, utilizing such applications can be an effective method in future revitalization work.

\subsection{Future Development in Language Revitalization}

Although there are numerous methods of language revitalization or language revival already in existence, many problems of endangered languages still remain unsolved. Khoisan language revitalization has thus far proven successful, but its future is unsecured. If future generations do not learn the language, there is still a danger of a second extinction. Simple documentation or revitalization cannot guarantee the survival of any language in the long run. Therefore, it's important to conduct further research on this issue to explore innovative and more efficient methods of revitalization. To make matters more urgent, as more languages are becoming endangered, the materials and speakers left for researchers to utilize are also decreasing. As time passes, the difficulty of revitalizing these languages rises exponentially. Therefore, further efforts from linguists and scholars are needed 
to ensure languages can be saved.

\section{Conclusion}

In the words of Lindsay Whaley, a Linguistics and Classics professor at Dartmouth College, "if a language goes extinct, it disappears completely. The culture is gone, and the history is gone, leaving no trace for us to review" (Whaley, personal communication, August 23, 2019). Language revitalization is necessary to prevent these kinds of cultural losses. This paper provides an overview of language revitalization through a case study of the Khoisan languages, detailing the historical causes of the language endangerment and subsequent language revitalization attempts to date. Despite numerous language revitalization attempts using the popular strategies of development of cultural pride, utilization of religion, and incorporation of cultural traditions and education, the Khoisan languages are still at risk of extinction. This continued endangerment demonstrates the challenging nature of language revitalization in general. In consideration of these challenges, this paper proceeds to offer suggestions for strategies for future revitalization efforts, such the incorporation of modern technology, social media, and apps into existing revitalization strategies. In summary, this paper provides a thorough discussion of the topic of language revitalization through a specific case study, outlining the importance of language preservation, the most effective strategies for revitalization along with the challenges presented by those strategies, and the work which remains in protecting the world's languages.

\section{References}

Ajala, A. (1983). The nature of African boundaries. Africa Spectrum, 18(2), 177-189. Retrieved October, 2019, from http://www.jstor.org/stable/40174114

Alicia. (2018, April 14). Language revival: How 7 communities are bringing languages back to life. Retrieved from https://bilingua.io/language-revival-bringing-back-languages-to-life

Babel runs backwards. (2004, December 29). Retrieved November, 2019, from https://www.economist.com/special-report/2004/12/29/babel-runs-backwards

Batibo, H. M. (2009). Language documentation as a strategy for the empowerment of the minority languages of Africa. In M. Matondo (Ed.), Selected Proceedings of the 38th Annual Conference on African Linguistics (pp. 193-203). Somerville, MA: Cascadilla Proceedings Project. Retrieved from http://www.lingref.com/cpp/acal/38/paper2147.pdf

Biwa, M. (2012). Weaving the past with threads of memory: Narratives and commemorations of the colonial war in Southern Namibia. Doctoral dissertation, University of the Western Cape. Retrieved from https://core.ac.uk/download/pdf/58914251.pdf

Bleek, W. H. I., \& Lloyd, L. C. (1911). Specimens of bushman folklore. G. Allen. Retrieved from https://www.sacred-texts.com/afr/sbf/index.htm

Chebanne, A. (2010). The Khoisan in Botswana-Can multicultural discourses redeem them? Journal of Multicultural Discourses, 5(2), 87-105. https://doi.org/10.1080/17447141003639801

Crystal, D. (2000). Language death. Cambridge University Press. https://doi.org/10.1017/CBO9781139106856

Crystal, D. (2008). By hook or by crook: A journey in search of English. Harper Perennial.

du Plessis, M. (2019). The Khoisan Languages of Southern Africa: Facts, theories and confusions. Critical Arts, 1-22. https://doi.org/10.1080/02560046.2019.1647256

Duolingo. (2019). 17 Amazing Duolingo Statistics (by the Numbers). Retrieved May 21, 2020 from https://forum.duolingo.com/comment/34061634/17-Amazing-Duolingo-Statistics-By-The-Numbers

Eisenlohr, P. (2004). Language Revitalization and New Technologies: Cultures of Electronic Mediation and the Refiguring of Communities. Annual Review of Anthropology, 33, 21-45. https://doi.org/10.1146/annurev.anthro.33.070203.143900

Greenberg, J. H. (1963). The Languages of Africa. International Journal of American Linguistics, 25(1).

Grosjean, F. (1982). Life with two languages: An Introduction to bilingualism. Harvard University Press.

Harshav, B. (2009). Flowers Have No Names: The revival of Hebrew as a living language after two thousand years was no miracle. Natural History, 118(1), 24-29.

Isa, B. Z., Ahmed, H. K., \& Grema, Y. (2014). Language death and endangered languages. IOSR Journal of Humanities and Social Science, 19(10), 46-48. https://doi.org/10.9790/0837-191064648

Khoisan Languages. (2020, June 06). Retrieved June 11, 2020, from


https://en.wikipedia.org/wiki/Khoisan_languages

Khoisan Language Family - Structure \& Writing - MustGo. (n.d.). Retrieved November, 2019, from https://www.mustgo.com/worldlanguages/khoisan-language-family/

Khomani, S. (2020). Retrieved May 21, 2020, from http://www.khomanisan.com/

Klass, P. (2017, July 10). Raising a Truly Bilingual Child. Retrieved September, 2019, from https://www.nytimes.com/2017/07/10/well/family/raising-a-truly-bilingual-child.html

Miller, A., Brugman, J., Sands, B., Namaseb, L., Exter, M., \& Collins, C. (2007). The sounds of Nluu: Place and airstream contrasts (vol. 16, pp. 101-106). Working Papers of the Cornell Phonetics Laboratory. Retrieved May 21, 2020, from https://conf.ling.cornell.edu/plab/paper/Miller_et_al_preprint.pdf

Miller-Ockhuizen, A. (2003). The phonetics and phonology of gutturals: A case study from Ju|'hoansi. In L. Horn (Ed.), Outstanding Dissertations in Linguistics Series. New York: Routledge. https://doi.org/10.4324/9780203506400

Ndhlovu, F. (2008). Language and African development: Theoretical reflections on the place of languages in African Studies. Nordic Journal of African Studies, 17, 137-151.

Richter, F. (2018). Infographic: Teens' Social Media Usage Is Drastically Increasing. Retrieved May 21, 2020 from https://www.statista.com/chart/15720/frequency-of-teenagers-social-media-use/

SABC Education Shows. (SABC Education). (2015, November 10). The Golden years 2 - Episode 24: Katrina Esau [video file]. Retrieved from https://www.youtube.com/watch?v=dIDI2VVOt2I

Sands, B. (2018). Language revitalization in Africa. The Oxford Handbook of Endangered Languages. https://doi.org/10.1093/oxfordhb/9780190610029.013.29

The Death of Language. (2018, December 10). Retrieved October, 2019, from https://www.kwintessential.co.uk/blog/news/the-death-of-language

Thompson, H. (2015, June 16). Half of all languages come from this one root tongue. Here's how it conquered the Earth. Retrieved November, from https://www.smithsonianmag.com/smart-news/watch-how-indo-european-languages-conquered-earth-1809 $55578 /$

Whaley, L. (2019, August). Endangered language revitalization. Eureka Workshop.

\section{Copyrights}

Copyright for this article is retained by the author, with first publication rights granted to the journal.

This is an open-access article distributed under the terms and conditions of the Creative Commons Attribution license (http://creativecommons.org/licenses/by/4.0/). 